\title{
Isolation, Simultaneous Quantification of Taxifolin and Taxifolin-3-O-rhamnoside and Validation by RPHPLC
}

\author{
Subashini Subramanian, Shakila Ramachandran*
}

\section{Subashini Subramanian, Shakila Ramachandran*}

\section{Department of Chemistry,}

Siddha Central Research Institute,

Anna Hospital Campus, Arumbakkam, Chennai, Tamil Nadu, INDIA.

\section{Correspondence}

\section{Dr. R Shakila}

Department of Chemistry, Siddha Central Research Institute, Anna Hospital Campus, Arumbakkam, Chennai-600106, Tamil Nadu, INDIA.

Email id: r.shakila@gov.in

\section{History}

- Submission Date: 16-10-2021;

- Review completed: 04-11-2021;

- Accepted Date: 21-12-2021

DOI : 10.5530/pres.14.1.6

Article Available online http://www.phcogres.com

Copyright

(C) 2022 Phcog.Net. This is an openaccess article distributed under the terms of the Creative Commons Attribution 4.0 International license

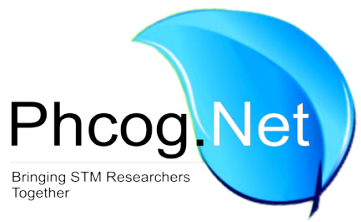

\begin{abstract}
Background: Taxifolin (TA) is a flavonoid that has antioxidant, hepatoprotective, antialzheimer, anti-hyperglycemic, cardiovascular, anti-inflammatory, anti-psoriatic and antialzheimer properties. Taxifolin 3-O-rhamnoside (TAR), a glycoside of taxifolin, has antioxidant, anticonvulsant, anticancer, anti-inflammatory, and immunosuppressive effects. Objectives: The goal of this study is to separate TA and TAR from Smilax china Linn. rhizomes, as well as to develop and validate a technique for simultaneous measurement of TA and TAR. Materials and Methods: The hydro alcoholic extract of the rhizome of $S$. china yielded TA and TAR. HPLC system was fitted with a $C_{18}$ column (shim-pack) of size $150 \mathrm{~mm} \times 4.6 \mathrm{~mm}$; $5 \mu$, with suitable eluting mixture of methanol: water $(90: 10 \mathrm{v} / \mathrm{v})$ at a flowing rate of $1 \mathrm{ml} / \mathrm{min}$ and at 254 $\mathrm{nm}$ wavelength for identification of peaks. Lab solution software was used to establish the quantification method for above-mentioned chemical compounds. Results: TAR and TA were separated using the proposed technique at $\mathrm{R}_{t} 2.917$ and 3.924 min respectively. Over the range of $0.1-0.8 \mu \mathrm{g} / \mathrm{ml}$, calibration curves were produced with a linear relationship $R^{2}>0.9941$ and 0.9963 , respectively. The relative standard deviation was less than $2 \%$. The percentage recoveries were shown to be between 97 and 102.1. TA and TAR had detection limits of 0.156 and $0.077 \mu \mathrm{g} / \mathrm{ml}$; quantification limits were 0.473 and $0.234 \mu \mathrm{g} / \mathrm{ml}$ respectively. The technique that was devised was simple, sensitive and specific. Conclusion: The newly designed RPHPLC technique has improved specificity, precision, and accuracy. The quality of $S$. china and other dietary supplements containing these two flavonoids may be successfully assessed by quantifying these two flavonoids and their glycosides.

Key words: Astilbin, Dihydroqucertin, 3,5,7,3',4'-pentahydroxy flavanone, Tuberculosis, Validation.
\end{abstract}

\section{INTRODUCTION}

Smilax china Linn, a member of the Smilacaceae family, grows widely in tropical and temperate locations around the world, particularly in East Asia. ${ }^{[1,2]}$ This plant is a perennial climber with aculeate pore skin and paired tendrils that help with climbing. Smilax china L. tubers have been practiced for treating TB, gout, tumour and inflammation according to several studies. ${ }^{[3-5]}$ The study about the Smilax genus has grown in popularity in recent years, particularly in Asia and Europe, as the existence of phenol compounds in few specie were found which can prevent and treat a variety of malignancies. Furthermore, plant extracts of the Smilax genus have antioxidant and pro-apoptotic properties. ${ }^{[6]}$ (2R,3R) Hayashi and Ouchi was the first one to isolate taxifolin3- $\beta$-O-rhamnoside from the rhizome of Astilbe thunbergii. ${ }^{[7]}$ Astilbin is another name of $(2 \mathrm{R}, 3 \mathrm{R})$ taxifolin-3- $\beta$-O-rhamnoside. It is also present in other plants consisting of Dimorphandra mollis, Psychotria prumfolia, Senna obtusifolia, Tithonia diversifolia, ${ }^{[8]}$ Heritiera littoralis, ${ }^{[9]}$ Engelhardtia roxburghiana, ${ }^{[10,11]}$ Smilacis glabrae, ${ }^{[12]}$ Smilacis chinae ${ }^{[13]}$ Drimys brasiliensis, ${ }^{[14]}$ Hymenaea courbaril, ${ }^{[15]}$ Hymenaea stigonocarpa ${ }^{[16]}$ Pieris japonica, ${ }^{[17]}$ previous research has suggested that astilbin has the potency to be used in both healthy supplements and medicine because of its various bioactivities, increasing liver injury immunological activity. ${ }^{[7]}$ Taxifolin (also known as 3,5,7,3,4'-pentahydroxy flavanone or dihydroquercetin) is a flavonoid and an integral ingredient of nutritional dietary supplements. It is also utilized as a nutritious meal that is high in antioxidants. Pseudotsuga taxifolia (Lindl.) Britton was the first plant to isolate it, followed by Larix gmelinii (Rupr.) Kuzen. syn Larix dahurica Turcz. ex Trautv. and Larix sibirica Ledeb, ${ }^{[18]}$ Milk thistle, ${ }^{[19]}$ onions, ${ }^{[20]}$ Douglas fir bark, ${ }^{[21]}$ and French maritime pine bark, ${ }^{[22]}$ are all sources of taxifolin. It can also be present in a variety of plants. It has hardly been utilised as a single component, although it may be found in several preparations such as silymarin (Legalon TM), Pycnogenol ${ }^{\circledR}$ and Venoruton ${ }^{\oplus}$. ${ }^{[23]}$

In previous research, taxifolin in the plasma of rabbit was determined and studied for pharmacokinetic 
using Shimadzu's high pressure liquid chromatography with a $\mathrm{C}_{18}$ column (Luna) with $150 \mathrm{~mm}$ length, $4.6 \mathrm{~mm}$ diameter and $5 \mathrm{~mm}$ particle size, pre-column $(2.0 \mathrm{~mm}$, the same adsorbent) and UV detector in two step linear gradient elution mode with acetonitrile and 0.3 percent trifloroacetic acid in water mobile phase and $0.1 \mathrm{ml}$ flow rate has been reported. ${ }^{[24]}$ In another study, method by UPLC-MS with sunfire TM $\mathrm{C}_{18}$ column $(2.1 \mathrm{~mm} \times 50 \mathrm{~mm}, 3.5 \mu \mathrm{m})$ and electrospray ionization technique using the mobile phase of acetonitrile and 0.3 percent acetic acid by eluting in gradient mode from 10 percent acetonitrile followed by 35 percent acetonitrile and then 10 percent acetonitrile for quantification in rat plasma has been reported. ${ }^{[25]}$

\section{MATERIALS AND METHODS}

\section{Solvents}

HPLC grade solvents viz., acetonitrile, methanol and deionized water were of are purchased from Merck. Hexane and ethyl acetate were of LR grade from Reachem Chemicals.

\section{Plant Material}

The proposed study's dried plant material was acquired from an industrial source in Chennai, Tamil Nadu. The Pharmacognosy department of our Institute authenticated and stored the specimen samples with them.

\section{Isolation}

Over silica gel, the hydroalcoholic extract (50 g) was column chromatographed (60-120 mesh). Eluted using various eutectic mixture like hexane: ethyl acetate combination ratios. Using a rota-vacuum, the comparable fractions were mixed and evaporated. Compound 1 (yield 56 $\mathrm{mg}$ ) was obtained from the fractions collected while eluting with hexane: ethyl acetate (80:20), whereas compound 2 (yield $65 \mathrm{mg}$ ) was obtained from the fractions collected while eluting with hexane: ethyl acetate (65:35). (Yield $135 \mathrm{mg}$ ). With a mobile phase of hexane: ethyl acetate $(6: 4, v / v)$, these compounds yielded a single spot at Rf 0.41 and 0.83 on TLC. NMR was used to analyze the spectral data, which was compared to taxifolin, ${ }^{[26]}$ and taxifolin 3-O-rhamnoside. ${ }^{[27]}$

\section{Instrumentation}

HPLC experiments utilized a Shimadzu LC-20AP (Shimadzu Corporation, Kyoto, Japan). Column oven, degassing unit, low pressure gradient unit and isocratic unit were all parts of the LC-20AP system. In this experiment, a quaternary mixing pump with low pressure, a Shimadzu SPD-M20A Photodiode-Array detector with isothermal flow cell, and an $\mathrm{RP}^{-\mathrm{C}_{18}}$ column with 20 -aliquot sample loop capacity, as well as a 20 microliter Hamilton injector were employed. The HPLC equipment collected and analysed data using lab solution. In order to get the UV spectra, a Shimadzu spectrometer was employed.

\section{Selection of Wavelength}

A standard $1 \mathrm{mg}$ per $\mathrm{ml}$ solution was made in methanol. The RP-C column was injected with $20 \mu \mathrm{g} / \mathrm{ml}$ solutions using the Hamilton injector and the UV spectra was acquired by scanning the standard solution between 190 and $800 \mathrm{~nm}$. Because of the maximum absorbance by TA and TAR were monitored in the eluents using a PDA detector at $254 \mathrm{~nm}$.

\section{Preparation of standard and sample solutions}

When making samples for the study, $10 \mathrm{mg}$ of the $S$. china sample was dissolved between three different solvents: ethanol, methanol, and an alcohol-based hydro-alcoholic solution. To make up the standards TA and TAR, $7 \mathrm{mg}$ of compounds was dissolved in $7 \mathrm{ml}$ of methanol in volumetric flasks $(1 \mathrm{mg} / \mathrm{ml})$. The mixture was then thoroughly mixed and filtered with Whatman filter paper before being filtered again through a $0.2 \mathrm{~m}$ membrane filter. To achieve the final concentration, the volume included up to the mark of methanol. The dilution series of 0.1, $0.2,0.4,0.6$, and $0.8 \mu \mathrm{g} / \mathrm{ml}$ were produced in methanol and utilized as destination concentrations at $100 \%$ from the standard stock solution described above.

\section{Assay of the compounds}

The ICH Protocol was used to design and validate a method for simultaneous quantification. The sample was tested three times with the optimum chromatographic settings. For each sample, chromatograms were made and the quantity of each was recorded, as well as the standard deviation and \% RSD. The RP-HPLC-developed approach for measuring compounds (TA and TAR) was validated in accordance with the standard criteria in terms of its specificity, linearity, sensitivity, reliability, limit of detection, and limit of quantification.

\section{RESULTS}

\section{Specificity/Selectivity}

Specificity refers to a method's ability to analyze analyte responses when other receivers and contaminants are present. To prove their sensitivity, S. china sample extracts were compared to a chromatogram of a reference solution for the presence of receivers, contaminants, and other degradation. One may observe what type of reaction one receive by varying the concentration of the analytes one is measuring using the linearity and range of an analytical technique. It was decided to evaluate the linearity of the proposed technique using $0.1-0.8 \mu \mathrm{g} / \mathrm{ml}$. In the mobile phase, these standards were prepared using a standard mother solution containing $1 \mathrm{mg} / \mathrm{ml}$ using optimum chromatographic conditions, the linearity standards were injected three times, and the chromatograms were recorded as evidence. To determine linearity, a graph was made with concentration $(\mu \mathrm{g} / \mathrm{ml})$ on the $\mathrm{X}$-axis and compound area (TA and TAR) on the Y-axis, and then the correlation coefficient was calculated.

\section{Precision and accuracy}

The precision of the proposed approach was tested using interday and intraday precision experiments. Five indiscriminate injections of five distinct concentrations, namely $0.1,0.2,0.4,0.6$, and $0.8 \mu \mathrm{g} / \mathrm{ml}$. They were employed to check the reliability of the approach once it had been done, and were injected the above mentioned samples on the same days. Internal accuracy was also examined by injecting the same samples on several days to see whether there was any variation. The average and relative percentage of the mean standard deviation were computed. In the recovery experiments, the accuracy of the methods was reported. It was accomplished using the conventional addition approach, i.e., by adding a known concentration standards to a known sample and analysing the results using the optimum chromatographic conditions The recovery tests were conducted at four different concentrations (0.1$0.8 \mu \mathrm{g} / \mathrm{ml}$ ) and the percentage of standard deviation, relative standard deviation and specific recovery were determined.

\section{Limit of detection and quantification}

Sensitive techniques are those that can detect analytes at very low concentrations. By testing the lowest concentration of standard solution by the newly established RP-HPLC techniques, the limit of detection and limit of quantitation were calculated. The LOD is the lowest detectable concentration of analyte that can produce a detectable response $(\mathrm{s} / \mathrm{n}$ ratio 3 ). The LOQ is the lowest concentration of an analyte at which a measurable response can be seen ( $\mathrm{s} / \mathrm{n}$ ratio 10 ). The formula used to determine LOD and LOQ values are: 


$$
\mathrm{LOD}=3.3 \sigma \div \mathrm{S} \text { and } \mathrm{LOQ}=10 \sigma \div \mathrm{S}
$$

Where $S=$ slope of the deviation curve and $\sigma=$ standard deviation.

\section{Robustness and Ruggedness}

Ruggedness and robustness of the method were assessed by altering the investigation parameters (analyst, reagents and columns) and enhancing the chromatographic conditions ( $\mathrm{pH}$ of solvents, composition of mobile phase, changing the ratios of mobile phase and rate of flow of mobile phase).

\section{System suitability}

The analytical development and validation include consideration of system adaption features to ensure the functionality of system. HPLC characteristics such as peak retention times $(\mathrm{R} t)$ and asymmetry factors (A) were assessed after four injections of the compounds (TA and TAR) at a concentration of $10 \mathrm{mg} / \mathrm{ml}$ each.

\section{DISCUSSION}

Shao et al. has isolated six phenolic compounds viz., engeletin, oxyresveratrol, piceid, resveratrol, scirpusin A and taxifolin-3-Oglycoside from ethyl acetate fraction of 95 percent ethanol extract of $S$. china rhizome by repeated column chromatography over silica gel and developed a HPLC method for the simultaneous determination of these phenolic compounds. The HPLC system contained a $\mathrm{C}_{18}$ (Zorbax $\mathrm{XDB})$ column eluted gradiently with acetonitrile and 0.02 percent phosphoric acid and the rate of flow was $1 \mathrm{ml} / \mathrm{min}$ and detected at $300 \mathrm{~nm} \cdot{ }^{[28]}$ Another study reported on the quantification of TA in a HPLC system with a $\mathrm{C}_{18}$ (Zorbax SB) column (250 mm x $4.6 \mathrm{~mm}$ inner dia, $5 \mu$ ) using the solvent mixture of acetonitrile (A) and 0.1 percent acetic acid solution (B) programmed in linear gradient elution of $15-20$ percent (A) in 0-15 min, and 20-40 percent (A) 15-40 min with a rate of flow of $1 \mathrm{ml} / \mathrm{min}$. The gradient method was observed in all of the conventional techniques, which used acetonitrile and acidified water solvents of changing composition. ${ }^{[10]}$ A better chromatographic technique was developed using the results of several trials with different mobile phase compositions. Finally, a 70:30 (v/v) mobile phase composed of methanol and water was selected on, which showed peak asymmetry at flow rates of one millilitre per minute. For the solid phase, a $150 \mathrm{~mm}$ x $4.6 \mathrm{~mm} \mathrm{C}_{18}$ column was used and measured the peaks at $254 \mathrm{~nm}$. The compound TAR was eluted in $2.917 \mathrm{~min}$, while the molecule TA took $3.924 \mathrm{~min}$ to elute. Before injecting the solvents into the HPLC system, they were filtered via a $0.45 \mu \mathrm{m}$ membrane filter made up of poly tetra fluoro ethylene. The chromatographic peaks were detected, recorded and processed using the lab solution software. Methanol, unlike ethanol or hydro alcohol, was shown to be the most effective solvent for extracting these compounds.

\section{Linearity}

For five different chemical concentrations, the calibration curve was compared to the matching peak region. Acceptable correlations were found between concentration and peak area for the compounds in the range of concentrations $(0.1-0.8 \mu \mathrm{g} / \mathrm{ml})$. When looking at the slope and intercept, it was found that 474.32 and 8225.5 were the values for the compounds (TA and TAR) correlation coefficient, which is more significant at 0.9999 . The graph of linearity is shown in Table 1 and Figure 1, respectively.

\section{Specificity}

The specificity/selectivity of the method was shown by injecting dilute solutions of standards (TA and TAR) and sample solution of $S$. china for checking the absence of co eluting peaks during the retention times of the

\begin{tabular}{ccc}
\multicolumn{2}{l}{ Table 1: Calibration curve data. } \\
\hline Regression parameters & TA & TAR \\
\hline Regression equation & $72919 \mathrm{x}+1191.7$ & $72088 \mathrm{x}-5432.1$ \\
Correlation coefficient $\left(\mathrm{R}^{2}\right)$ & 0.9941 & 0.9963 \\
Slope & 72919 & 72088 \\
Y-intercept & 1191.7 & 5432.1 \\
Concentration range & $0.1,0.2 .0 .4,0.6$ and 0.8 & $0.1,0.2 .0 .4,0.6$ and \\
$(\mu \mathrm{mL})$ & & 0.8 \\
Number of points & 2 & 2 \\
\hline
\end{tabular}
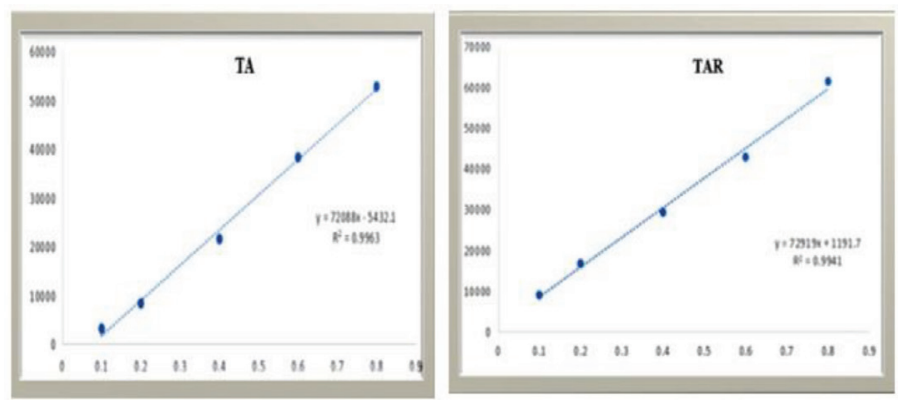

Figure 1: Linearity graph of taxifolin (TA) and taxifolin 3-O-rhamnoside (TAR).

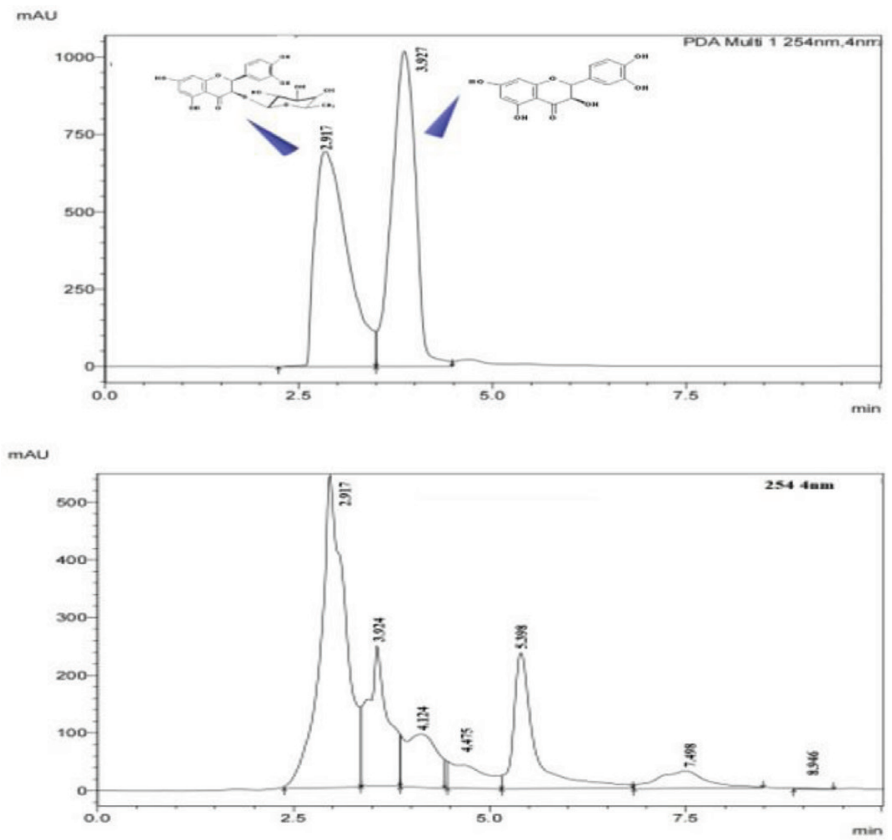

Figure 2: HPLC chromatogram of standard mixture of TAR and TA and methanol extract of $S$. china.

compounds (2.917 and 3.924) (Figure 2). There were no co-eluent peaks; the form of it is symmetric and crisp, demonstrating the specificity of the improved chromatographic technique. Three replicates of the sample solutions and standard were used in the analysis.

\section{Precision and Accuracy}

The accuracy of the developed method was represented as the average recovery for four distinct concentration levels $(0.1,0.4,0.6,0.8 \mu \mathrm{g} /$ $\mathrm{ml})$. At each stage, a three-fold analysis was performed. The percentage 
Table 2: Mean recovery of TA and TAR.

\begin{tabular}{cccccc}
\hline & TA & & \multicolumn{3}{c}{ TAR } \\
\hline $\begin{array}{c}\text { Amount } \\
\text { injected } \\
(\mu \mathrm{g} / \mathrm{mL})\end{array}$ & $\begin{array}{c}\text { Amount } \\
\text { recovered } \\
(\mu \mathrm{g} / \mathrm{mL})\end{array}$ & $\begin{array}{c}\% \\
\text { Recovery }\end{array}$ & $\begin{array}{c}\text { Amount } \\
\text { injected } \\
(\mu \mathrm{g} / \mathrm{mL})\end{array}$ & $\begin{array}{c}\text { Amount } \\
\text { recovered } \\
(\mu \mathrm{g} / \mathrm{mL})\end{array}$ & $\begin{array}{c}\% \\
\text { Recovery }\end{array}$ \\
\hline 0.1 & 0.097 & 97 & 0.1 & 0.098 & 98 \\
0.4 & 0.395 & 98.75 & 0.4 & 0.388 & 97.0 \\
0.6 & 0.613 & 102.1 & 0.6 & 0.598 & 99.6 \\
0.8 & 0.807 & 100.8 & 0.8 & 0.801 & 100.12 \\
\hline
\end{tabular}

Table 3: Summary of validation parameters.

\begin{tabular}{ccc}
\hline Parameter & TA & TAR \\
\hline Linearity $\left(R^{2}\right)$ & 0.9941 & 0.9963 \\
Intra-day precision (\% RSD) & 1.945 & 1.622 \\
Inter-day precision (\% RSD) & 1.715 & 1.812 \\
LOD $(\mu \mathrm{g} / \mathrm{mL})$ & 0.156 & 0.077 \\
LOQ $(\mu \mathrm{g} / \mathrm{mL})$ & 0.473 & 0.234 \\
Accuracy $(\%)$ & 99.66 & 98.68 \\
Robustness & Robust & Robust \\
Specificity & Specific & Specific \\
\hline
\end{tabular}

average recovery was computed (Table 2). The accuracy was between 97 and 102.1 percent. The developed approach was utilized for chemical analysis (TA and TAR). The percent RSD for the assay experiments performed on actual samples was less than $2 \%$, indicating the method's accuracy. The intraday and interday precision experiments revealed the percentage RSD value less than 2 indicating the accuracy of the method.

\section{Limit of Detection and Quantification}

The limit of detection and quantification shows the sensitivity of the developed method. The LOD and LOQ were determined as 0.156 and $0.473 \mu \mathrm{g} / \mathrm{ml}$ for the TA component and 0.077 and $0.234 \mu \mathrm{g} / \mathrm{ml}$ for the TAR component, showing the sensitivity of the procedure.

\section{Robustness and Ruggedness}

The flow rate $(1 \mathrm{ml} / \mathrm{min}), \mathrm{pH}$, column temperature and organic phase composition were all varied to see the robustness of the technique. As a result of these differences, the chromatographic parameters didn't alter much even after varying the experimental settings. A fast and sensitive reverse phase HPLC method has been established to quantify the compounds TA and TAR, with run times of 2.917 and $3.924 \mathrm{~min}$, respectively. The sample's retention time were unaltered (TA and TAR).

\section{System suitability}

The compatibility of the system was evaluated by executing the tests and noting changes in dissociation, retention time and peak distortion with four replicating injections of the standard at the working concentration. System appropriateness has been incorporated through permissible limits which are shown in Table 3.

\section{CONCLUSION}

An RP-HPLC technique that is quick, affordable, sensitivity, accurate, and precise has indeed been established and validated for method as per ICH criteria. In this case, the technique accuracy was shown by a relative standard deviation of 0.9982 . Compounds TA and TAR exhibited excellent linearity in the concentration range $(0.1-0.8 \mu \mathrm{g} / \mathrm{ml})$. During the retention period of the chemicals in the sample solution, no interference was found (TA and TAR). The current verified technique has a recovery rate of $97 \%-102 \%$ on average. To sum up, a quick reverse phase HPLC technique was developed and validated for measurement of components TA and TAR in S. china extracts and other dietary supplements. This approach is accurate, precise, as well as prompt.

\section{ACKNOWLEDGEMENT}

Authors are thankful to The Director General, Central Council for Research in Siddha and The Assistant Director I/c, Siddha Central Research Institute for their support and encouragement.

\section{Funding}

Funded by Central Council for Research in Siddha under Intramural Research Project Scheme vide sanction no.28/2016-17 dated 26.09.2016.

\section{CONFLICT OF INTEREST}

The authors declare no conflict of interest

\section{REFERENCES}

1. Seo HK, Lee JH, Kim HS, Lee CK, Lee SC. Antioxidant and antimicrobial activities of Smilax china L. leaf extracts. Food Sci Biotechnol. 2012;21(6):1723-7, doi: 10.1007/s10068-012-0229-4

2. Chen L, Yin H, Lan Z, Ma S, Zhang C, Yang Z, et al. Anti-hyperuricemic and nephroprotective effects of Smilax china L J Ethnopharmacol. 2011;135(2):399-405 doi: 10.1016/j.jep.2011.03.033, PMID 21420478.

3. Huang HL, Lu ZQ, Chen GT, Zhang JQ, WangW, Yang M, Guo D. PhenylpropanoidSubstituted Catechins and Epicatechins from Smilax china. Helv Chim Acta. 2007 Sep;90(9):1751-7, doi: 10.1002/HLCA.200790184.

4. Li YL, Gan GP, Zhang HZ, Wu HZ, Li CL, Huang YP, et al. A flavonoid glycoside isolated from Smilax china $L$. rhizome in vitro anticancer effects on human cancer cell lines. J Ethnopharmacol. 2007;113(1):115-24, doi: 10.1016/j. jep.2007.05.016, PMID 17606345.

5. Shu XS, Gao ZH, Yang XL. Anti-inflammatory and anti-nociceptive activities of Smilax china L. aqueous extract. J Ethnopharmacol. 2006;103(3):327-32, doi: 10.1016/j.jep.2005.08.004, PMID 16387460.

6. Ruan JL, Zou J, Cai YL. A study of the anti-inflammatory components of Smilax china. Herald Med. 2005;24:670-2.

7. Gao Y, Su Y, Qu L, Xu S, Meng L, Cai SQ, et al. Mitochondrial apoptosis contributes to the anti-cancer effect of Smilax glabra Roxb Toxicol Lett. 2011;207(2):112-20, doi: 10.1016/j.toxlet.2011.08.024, PMID 21920417.

8. Fouad HA, Faroni LR, De Souza Tavares W, Ribeiro RC, De Sousa Freitas S, Zanuncio JCFouad HA, et al. Botanical extracts of plants from the Brazilian Ccerrado for the integrated management of Sitotroga cerealella (Lepidoptera: Gelechiidae) in stored grain. J Stored Prod Res.. 2014; 57: 6-11. https://doi org/10.1016/j.jspr.2014.01.001doi: 10.1016/j.jspr.2014.01.001.

9. Christopher R, Nyandoro SS, Chacha M, De Koning CB. A new cinnamoylglycoflavonoid, antimycobacterial and antioxidant constituents from Heritiera littoralis leaf extracts. Nat Prod Res. 2014;28(6):351-8. doi: 10.1080/14786419.2013.863202, PMID 24443810.

10. Huang H, Cheng Z, Shi H, Xin W, Wang TT, Yu LL. Isolation and characterization of two flavonoids, engeletin and astilbin, from the leaves of Engelhardia roxburghiana and their potential anti-inflammatory properties. J Agric Food Chem. 2011;59(9):4562-9, doi: 10.1021/jf2002969, PMID 21476602.

11. Xin W, Huang $H$, Yu L, Shi H, Sheng Y, Wang TTY, et al. Three new flavanonol glycosides from leaves of Engelhardtia roxburghiana, and their anti-inflammation, anti-proliferative and antioxidant properties. Food Chem. 2012;132(2):788-98, doi: 10.1016/j.foodchem.2011.11.038.

12. Xu WA, Yin L, Pan HY, Shi L, Xu L, Zhang $X$, et al. Study on the correlation between constituents detected in serum from Rhizoma Smilacis Glabrae and the reduction of uric acid levels in hyperuricemia. J Ethnopharmacol. 2013;150(2):747-54. doi: 10.1016/j.jep.2013.09.024. PMID 24140588.

13. Zhang QF, Guo YX, Shangguan X, Zheng G, Wang WJ. Antioxidant and antiproliferative activity of rhizoma Smilacis chinae extracts and main constituents. Food Chem. 2012;133(1):140-5, doi: 10.1016/j.foodchem.2012.01.008.

14. Mecchi MC, Lago JH. Chemical constituents derived from Drimys brasiliensis Miers (Winteraceae). Nat Prod Res. 2013;27(20):1927-9, doi: 10.1080/14786419.2013.782491, PMID 23537128.

15. Dimech GS, Soares LA, Ferreira MA, De Oliveira AG, Carvalho Mda C, Ximenes EA. Phytochemical and antibacterial investigations of the extracts and fractions from the stem bark of Hymenaea stigonocarpa Mart. ex Hayne and effect on ultrastructure of Staphylococcus aureus induced by hydroalcoholic extract. Scientific World Journal. 2013;2013:862763. doi: 10.1155/2013/862763. PMID 24396311. 
16. Li YP, Li YH, Zhong JD, Li RT. Antioxidant phenolic glycoside and flavonoids from Pieris japonica. J Asian Nat Prod Res. 2013;15(8):875-9, doi: 10.1080/10286020.2013.803475, PMID 23796053.

17. Wang J, Zhao Y, Xu Q. Astilbin prevents concanavalin A-induced liver injury by reducing TNF-alpha production andT lymphocytes adhesion. J Pharm Pharmacol. 2004;56(4):495-502, doi: 10.1211/0022357023033, PMID 15104095.

18. Pew JC. A flavonone from Douglas-fir heartwood. J Am Chem Soc. 1948;70(9):3031-4. doi: 10.1021/ja01189a059, PMID 18882535.

19. Wallace SN, Carrier DJ, Clausen EC. Batch solvent extraction of flavanolignans from milk thistle (Silybum marianum L. Gaertner). Phytochem Anal. 2005;16(1):7-16. doi: 10.1002/pca.803. PMID 15688950.

20. Slimestad R, Fossen T, Vågen IM. Onions: A source of unique dietary flavonoids. J Agric Food Chem. 2007;55(25):10067-80. doi: 10.1021/jf0712503, PMID 17997520.

21. Kiehlmann E, Li EPM. Isomerization of dihydroquercetin. J Nat Prod. 1995:58(3):450-5. doi: 10.1021/np50117a018 R. Slimestad R, Fossen T, Vågen IM. Onions: A source of unique dietary flavonoids. J Agric Food Chem. 2007;55(25):10067-80, doi: 10.1021/jf0712503, PMID 17997520.

22. Rohdewald P. A review of the French maritime pine bark extract (Pycnogenol), a herbal medication with a diverse clinical pharmacology. Int J Clin Pharmacol Ther. 2002;40(4):158-68. doi: 10.5414/cpp40158, PMID 11996210.
23. Rohdewald P. A review of the French maritime pine bark extract (Pycnogenol), a herbal medication with a diverse clinical pharmacology. Int J Clin Pharmacol Ther. 2002;40(4):158-68. doi: 10.5414/cpp40158. PMID 11996210.

24. Pozharitskaya ON, Karlina MV, Shikov AN, Kosman VM, Makarova MN, Makarov VG. Determination and pharmacokinetic study of taxifolin in rabbit plasma by high-performance liquid chromatography. Phytomedicine. 2009;16(2-3):244-51. doi: 10.1016/j.phymed.2008.10.002, PMID 19110406.

25. Zhang OF, Guo YX, Shangguan X, Zheng G, Wang WJ. Identification and quantification of polyphenols in rhizoma Smilacis chinae by HPLC/DAD/ ESI-MS/MS. J Liq Chromatogr Relat Technol. 2013;36(16):2251-60. doi: 10.1080/10826076.2012.720326 ON

26. Zhou S, Shao Y, Fu J, Xiang L, Zheng Y, LiW. Characterization and Quantification of Taxifolin Related Flavonoids in Larix olgensis Henry Var. koreana Nakai Extract Analysis and its Antioxidant Activity Assay. Int J Pharmacol. 2018;14(4):534-45. doi: 10.3923/ijp.2018.534.545.

27. Wang X, Xia H, Xing F, Deng G, Shen Q, Zeng S. A highly sensitive and robust UPLC-MS with electrospray ionization method for quantitation of taxifolin in rat plasma. J Chromatogr B Analyt Technol Biomed Life Sci. 2009;877(18-19):1778-86. doi: 10.1016/j.jchromb.2009.04.037, PMID 19464238.

28. Shao B, Guo HZ, CuiYJ, Liu AH, Yu HL, Guo H, et al. Simultaneous determination of six major stilbenes and flavonoids in Smilax china by high performance liquid chromatography. J Pharm Biomed Anal. 2007;44):737-42.
GRAPHICAL ABSTRACT

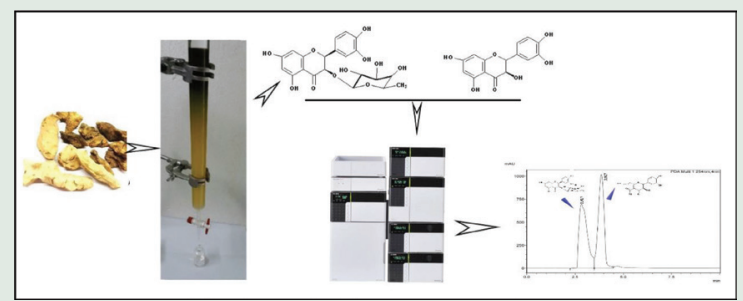

\section{SUMMARY}

The taxifolin and taxifolin 3-O-rhamnoside were isolated from the hydro alcoholic extract of S. china rhizome. RP-HPLC method was developed to quantitatively estimate taxifolin and taxifolin 3-O-rhamnoside. Rt of the compounds were 2.917 (taxifolin 3-O-rhamnoside) and $3.924 \mathrm{~min}$ (taxifolin). The linearity was achieved in the range of $0.1-0.8 \mu \mathrm{g} / \mathrm{ml}$; the linear relationship $\mathrm{r} 2>$ 0.9963 and 0.9941 respectively; $<2 \%$ relative standard deviation; percentage recoveries were between 97 and 102.1. TA and TAR had detection limits of 0.156 and $0.077 \mu \mathrm{g} / \mathrm{ml}$; quantification limits of 0.473 and $0.234 \mu \mathrm{g} / \mathrm{ml}$ respectively.

Cite this article: Subashini S, Shakila R. Isolation, Simultaneous Quantification of Taxifolin andTaxifolin-3-O-rhamnoside and Validation by RPHPLC. Pharmacog Res. 2022;14(1):30-4. 